\title{
Review Article \\ Effect of Transcriptional Regulator ID3 on Pulmonary Arterial Hypertension and Hereditary Hemorrhagic Telangiectasia
}

\author{
Vincent Avecilla $\mathbb{B D}^{1,2}$ \\ ${ }^{1}$ Department of Environmental Health Sciences, Robert Stempel College of Public Health \& Social Work, \\ Florida International University, Miami, FL 33199, USA \\ ${ }^{2}$ Celgene Corporation, Summit, NJ 07901, USA \\ Correspondence should be addressed to Vincent Avecilla; vavec001@fiu.edu
}

Received 12 March 2019; Accepted 26 June 2019; Published 11 July 2019

Academic Editor: Robert M. Schainfeld

Copyright (C) 2019 Vincent Avecilla. This is an open access article distributed under the Creative Commons Attribution License, which permits unrestricted use, distribution, and reproduction in any medium, provided the original work is properly cited.

\begin{abstract}
Pulmonary arterial hypertension (PAH) can be discovered in patients who have a loss of function mutation of activin A receptor-like type 1 (ACVRL1) gene, a bone morphogenetic protein $(B M P)$ type 1 receptor. Additionally, ACVRL1 mutations can lead to hereditary hemorrhagic telangiectasia (HHT), also known as Rendu-Osler-Weber disease, an autosomal dominant inherited disease that results in mucocutaneous telangiectasia and arteriovenous malformations (AVMs). Transcriptional regulator Inhibitor of DNABinding/Differentiation-3 (ID3) has been demonstrated to be involved in both PAH and HTT; however, the role of its overlapping molecular mechanistic effects has yet to be seen. This review will focus on the existing understanding of how ID3 may contribute to molecular involvement and perturbations thus altering both PAH and HHT outcomes. Improved understanding of how ID3 mediates these pathways will likely provide knowledge in the inhibition and regulation of these diseases through targeted therapies.
\end{abstract}

\section{Introduction}

Inhibitor of DNA-Binding/Differentiation-3 (ID3) is part of the ID family of proteins (helix-loop-helix) programmed by an instant-early gene responsive to oxidative stress and mitogenic indicators. Known as a transcriptional regulator that prevents stem cell differentiation and promotes cell cycle progression, ID3 has also been demonstrated to exhibit overlapping function as a gene knockout dependent on cellular context $[1,2]$. With regard to the vasculature, ID3 is important in embryonic vasculogenesis as well as endothelial cell activation [1, 3, 4]. Given that these functions are observed in endothelial cells from diseased vasculature [5], ID3 may mediate pulmonary dysfunction often found in individuals with cardiopulmonary disease such as pulmonary arterial hypertension (PAH), hereditary hemorrhagic telangiectasia (HHT), and atherosclerosis [6-10]. Furthermore, ID3 has been demonstrated to be a downstream target of the TGF $\beta /$ BMP7 signaling pathway, which has been known to play a significant role in various cellular processes such as migration, apoptosis, and proliferation alongside the processes of angiogenesis using two pathways: ALK5SMAD2/3 pathway and ALK1-SMAD1/5/8 pathway, important processes/pathways involved in PAH and HHT [11-14]. An enhanced understanding of interaction between ID3 and overlapping molecular mechanisms that can be mediated in $\mathrm{PAH}$ and HHT is essential in strengthening our complete understanding of how transcriptional regulators such as ID3 can modify PAH and HHT outcomes. Additional study in these particular areas may show both more effective or innovative therapeutic modalities and provide strategies for the future.

\section{Inhibitor of DNA-Binding/Differentiation-3 (ID3)}

ID3 is part of a family of proteins (ID1, ID2, ID3, ID4). The ID family shares a widespread amino acid homology within their domain (helix-loop-helix; 69-78\%) [2, 15]. Studies have shown that in genetically engineered mice, the significance of $i d 3$ in embryonic cell differentiation and development [16]. In dissimilarity, id1-id3 knockout mice have demonstrated 
neuronal differentiation, irregular vascularization of the brain, and cardiac deficiencies $[17,18]$ that were embryonically fatal. Reports indicate that $I D 3$ is greatly expressed in embryonic tissue however decreases as cells differentiate [2]. The expression of ID3 in adult tissues suggests a particular context and inclines to be at its peak in undifferentiated and proliferating cells. ID3 expression has been described as being stimulated by different stimuli in various cell types [19].

ID3 was originally recognized as a serum inducible instant-early gene in fibroblasts of mice that peak transcriptionally at 1 hour [20,21]. ID3 expression consequently has also been described to be biphasic with leading stimulus at 1 hour following a secondary burst of 24 hour as in the event of tissue regeneration after injury. ID3 proteinprotein interaction occurs in mammals through the HLH transcriptional factors E proteins, which include HEB, E22, and E12/47. TCF12, TCF3, and TCF4 genes encode these E proteins, respectively [22]. ID3 plays an essential function in cell proliferation through its connections with $\mathrm{E}$ proteins. E proteins have been demonstrated to bind the E-box sequence in the promoter $\mathrm{p} 21^{\mathrm{Cip} 1}$ and trigger its transcription [23]. In perspective of the cell cycle, ID3 stimulates cell cycle progression by the inhibition of $\mathrm{p} 21^{\mathrm{Cip} 1}$ expression. Protein-protein interactions particularly with ID3 and E proteins can disturb their capability of binding gene promoters and thus block transcriptional initiation by these factors [24]. Furthermore, ID3 has been revealed to inhibit $\mathrm{E}$ proteins from stimulating the $\mathrm{p} 21^{\text {Cip1 }}$ promoter in proliferating vascular cells [25].

ID3 has been indicated to control the binding of transcription factor 3 (TCF3) to the E-box motif in target gene promoters [26]. It has been reported that TCF3 represses the SOX2, NANOG, and OCT4 expression that contributes to cell differentiation [20]. Previous research has displayed overexpression, which increased both SOX2 and OCT4 expression in endothelial cells. This resulted in a population of cells that were positive for molecular stemness signature CD133+ VEGFR3+ CD34+ [27]. These endothelial stem cells were differentiated into neuron and smooth muscle cells. Based on this information, ID3 maintains cells in a noncommittal state by counteracting the repression of pluripotency factors by TCF3.

2.1. Pulmonary Arterial Hypertension (PAH). PAH is an infrequent but severe vascular disorder with increased pulmonary arterial pressure (PAP) as an outcome of vascular remodeling. PAH is categorized by an increased mean PAP (of $\geq 25 \mathrm{mmHg}$ at rest), increased pulmonary vascular resistance (PVR) of $>3$ Wood units, and a pulmonary capillary wedge pressure (PAWP) $\leq 15 \mathrm{mmHg}$, given all the gold standard measurement is a right heart catheterization (RHC). Nonetheless, echocardiogram can additionally give an assessment of the severity of the disease assessing right ventricular pressure and estimating secondary signs of right ventricle strain [28]. PAH is connected with various aspects and conditions. Certain drugs have been linked with the development of $\mathrm{PAH}$, including methamphetamines and anorexigens. Additionally, portal hypertension, connective tissue disease, and human immunodeficiency virus can result in PAH.

Heritable PAH (HPAH) diagnosis is pertinent when numerous genetic mutations are discovered. Bone morphogenetic protein receptor 2 (BMPR2) mutations are found in $75 \%$ of patients in this category [29-31]. The remaining $25 \%$ of patients are additionally connected with other genetic mutations as well. These include BMP9, SMAD3, ENG, and ACVLR1, which are also connected with HHT $[32,33]$. These can all be found to encode for proteins that play a function in the transforming factor-beta (TGF- $\beta$ ) signaling pathway. Furthermore, BMPR 2 deficiency has been previously seen to disrupt pulmonary vascular changes causing various defects in both systemic and heart circulation [28]. BMP signaling is tied into the pathogenesis of atherosclerosis and BMPR2 mutations appear to produce unique singular fibrovascular lesions, affecting larger bronchial arteries. This could explain why increased quantities of hemoptysis are seen in PAH with $B M P R 2$ mutations [28-30].

\subsection{Hereditary Hemorrhagic Telangiectasia (HHT). HHT is} an autosomal dominant inherited disease that affects 1 in 5000 individuals worldwide. Arteriovenous malformations (AVMs) and mucocutaneous telangiectasia are outcomes of vascular dysplasia. AVMs can hypothetically cultivate in every organ; however, most affected organs are the liver, brain, and lung. These AVMs are vulnerable to hemorrhage and rupture, which leads to major morbidity and mortality. Pulmonary AVMs result in blood flow from the pulmonary artery to the pulmonary vein, resulting in a decreased filtering volume of the pulmonary capillary bed. Complications from pulmonary AVMs therefore include paradoxal emboli and hypoxemia. To screen for pulmonary AVMs in HHT patients, a contrast echocardiogram can be used [34]. In order to decrease the risk of these severe problems, patients should be treated with an endovascular intervention that occludes the feeding of the pulmonary AVM with vascular plugs or coils also known as an embolization [35]. Vascular malformation is existent in $32-78 \%$ of HHT patients. This occurs in three various types including hepatic artery to hepatic vein, portal vein to hepatic vein, and/or shunting from hepatic artery to portal vein $[36,37]$. Additionally, these various AVMs can be directly involved in the vascular defects and impaired angiogenesis observed in HHT, which can be essentially elucidated by the breakdown of the endothelial cells [35-37].

The most essential clinical feature of HHT is epistaxis, from which $96 \%$ of patients suffer with HHT and additionally more than $50 \%$ before the age of 20 years old $[38,39]$. A majority of cases are caused by mutations in the ACVRL1 or $E N G$ genes. These mutations result in decreased levels of functional proteins of ALK1 and Endoglin due to haploinsufficiency [40]. Another disease-triggering mutation has been found in the SMAD4 gene, which results in a grouping of HHT and juvenile polyposis syndrome [41]. However, this mutation is rarer compared with others and only found in $1-2 \%$ of HHT patients. Most families associated with HHT have a distinctive mutation and more than 900 mutations are defined [42]. Mutations that cause HHT type 1 such as $E N G$ are characterized by a higher frequency of cerebral and 


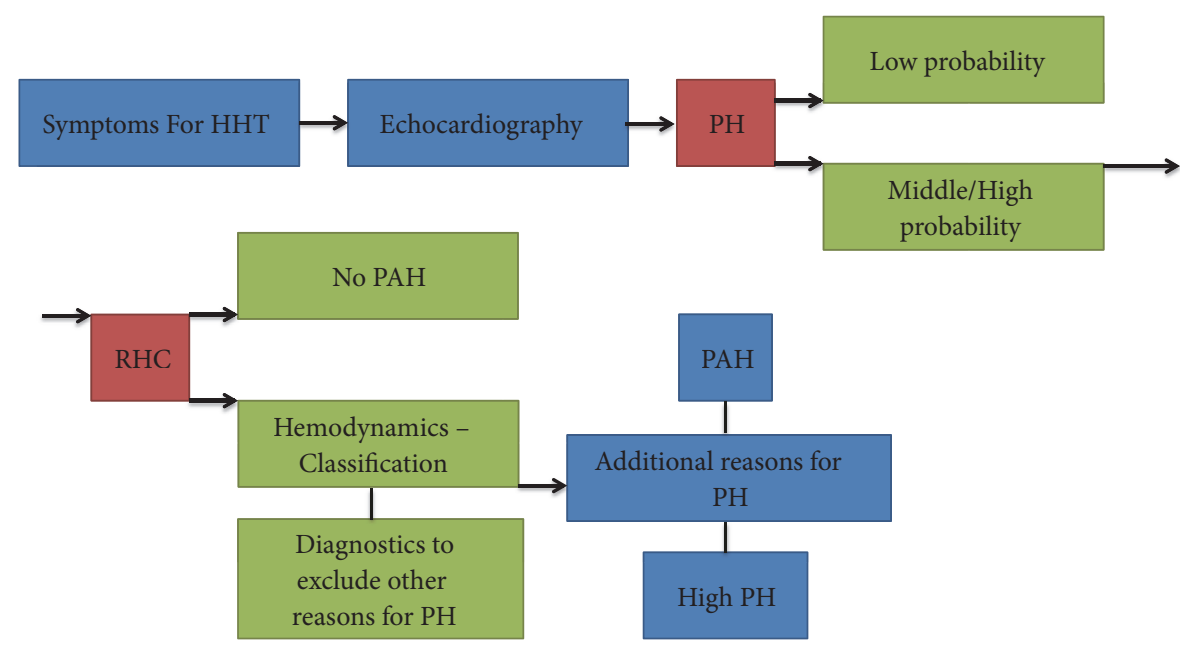

FIGURE 1: Flow chart of PH diagnosis in HHT. Abbreviations: HHT: hereditary hemorrhagic telangiectasia; PH: pulmonary hypertension; RHC: right heart catherization; PAH: pulmonary arterial hypertension.

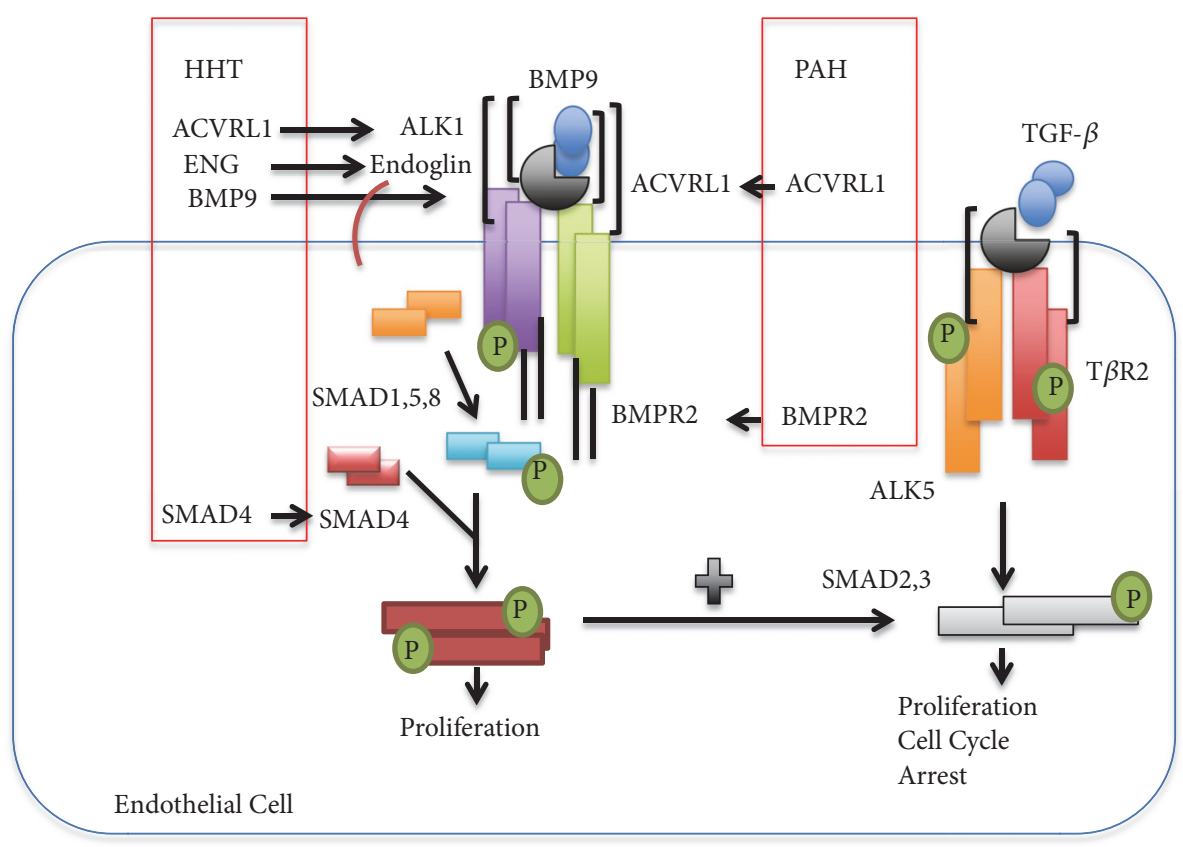

FIgURE 2: Diagram of the BMP9 and TGF- $\beta$ pathway and involved genes and proteins in PAH and HHT. Two pathways are displayed: ALK1/SMAD1-5 and ALK5/SMAD2-3. Abbreviations: P: phosphorylation.

pulmonary AVMs, epistaxis, and mucocutaneous telangiectasia compared to ACVRL1 mutations or HHT type 2. Most indications with $\mathrm{HHT}$ are progressive with age. Clinical signs are not only in age and subtype but also variable in severity between families with like mutations [43]. Genetic modifiers and etiological influences are considered to elucidate this clinical inconsistency [44]. Distinguishing between common symptoms of HHT and HHT complicated by PAH can be a perplexing endeavor. HHT patients frequently experience shortness of breath, exhaustion, and exercise intolerance due to hypoxemia and anemia resultant of pulmonary AVMs, psychological strain of a chronic disease, and epistaxis. Diagnostic management of $\mathrm{PH}$ in HHT is contingent on the existence of the symptoms as seen in Figure 1. If a patients' physical exam or history indicates $\mathrm{PH}$, an echocardiogram should be implemented to measure the likelihood of $\mathrm{PH}$.

2.3. Molecular Mechanisms of PAH and HHT. Signaling pathway families such as TGF- $\beta$ have been considered to play an essential role in various cellular activities such as apoptosis, proliferation, and migration [45]. A complex pathway, TGF- $\beta$, plays an important part in the process of angiogenesis using two signaling pathways: ALK1-Smad 1/5/8 pathway and activin receptor-like kinase 5 (ALK5)-Smad2/3 pathway as demonstrated in Figure $2[13,14]$. When vessels are produced, ECs migrate and proliferate. Once the wall 
of the capillary is developed, pericytes aid in stabilizing the vessel and inhibit endothelial migration and proliferation. This ultimately leads to vascular maturation, in which ALK5 plays significant role. Upregulation of Endoglin via ALK1 is a necessary receptor in the TGF- $\beta / \mathrm{BMP}$ signaling pathway, which is specifically expressed on proliferating ECs. Additionally, it has been established that endoglin counterbalances the steadying function of ALK5 [46, 47]. ACVRL1 and $E N G$ mutations disturb TGF- $\beta / \mathrm{BMP}$ signaling, thus modifying pericyte recruitment and EC tubulogenesis triggering irregular capillary maturation and formation leading to vascular hyperbranching, AVMs, and venous expansion elucidating the irregular morphogenesis of vascular in HHT $[13,48]$.

Vascular function is also regulated by ECs through mediating the production of vasodilators, vasoconstrictors, and both inhibition and activation of SMCs. Outcomes due to inhibition of apoptosis of SMCs can lead to vascular remodeling and proliferation, eventually causing PAH. This outcome can be due to the disruption of BMP signaling and the SMAD1,5,8 pathway, as a consequence of an ACVRL1 and BMPR2 mutation [49-51]. However, both HHT and $\mathrm{PAH}$ originate in deficiencies in the ALK1/BMP9/Endoglin pathway. A signaling complex between ALK1 and BMPR2 is formed, which responds to BMP9 through binding with high affinity to Endoglin and ALK1 $[32,52]$. Studies have indicated that BMP9 has been used in animal studies to treat PAH by stimulating $B M P R 2$ signaling. Additionally, the mutation of BMP9 can lead to syndrome with similar characteristics with [53-55]. Based on these lines of evidence, it may be plausible that BMP9 may have therapeutic benefits on HHT.

Difficulties of HHT can be furthered by heritable pulmonary arterial hypertension (HPAH); however, this is a rare case. Various mutations such as ACVRL1 have been explained in HPAH patients but there seems to be a predominance of mutations in the nonactivating nondownregulating box (NANDOR) [42]. Nevertheless, most family members of HHT patients with HPAH will not develop HPAH, which suggests that further environmental or genetic influences are needed to develop HPAH characteristics [56]. Information of this disease grouping of PAH and HHT is significant while this particular grouping frequently leads to worse results than PAH alone [56]. A study by Li et al. compared HHT-PAH patients to IPAH patients, assessing their prognosis. Oneand three-year survival rates were individually $78 \%$ and $53 \%$ for HHT-PAH patients, suggestively lower than patients with IPAH one- and three-year survival rates at $91 \%$ and $74 \%$ individually [56]. SMAD4 in the pathogenesis of HPAH is not completely known. While there are no HHT connected SMAD4 mutation carriers defined with $\mathrm{HPAH}$, there are two PAH patients in whom a mutation in the SMAD4 gene is established [57]. Both diseases share differences between men and women. Epidemiological data demonstrates female predominance in several types of $\mathrm{PAH}$ and life expectancy with HHT produced by an ENG mutation [58, 59]. It is assumed that female hormones play an essential role in both diseases; nonetheless, the particular mechanisms are not yet completely comprehended [60-62].
2.4. Influence of ID3 on PAH and HHT. ID proteins are downstream targets of the BMP signaling pathway. While literature evidence is limited, influence of ID3 on both PAH an HHT has been demonstrated as seen in Table 1 through pathways previously highlighted in this review paper. Mutations in the BMPR2 gene, encoding the type II BMP receptor, have been previously identified in patients with $\mathrm{PAH}$, implicating $\mathrm{BMP}$ signaling in $\mathrm{PAH}$. BMP receptors $\mathrm{Ib}$ and II together with $S M A D$ 4,5,6, and 8 were downregulated in lungs but not kidneys of monocrotaline (MCT) rats. Expression of BMP/SMAD target genes ID1 \& ID3 and SMAD1 phosphorylation was decreased. Induction of the BMP/SMADresponsive component of the ID1 promoter, SMAD expression, and SMAD1 phosphorylation demonstrated a decrease in pulmonary arterial smooth muscle cells (PASMCs) from MCT-inoculated rats. Due to impaired BMP/SMAD signaling, the PASMCs from the MCT-inoculated rats were defiant to apoptosis stimulated by BMP7 and BMP4. Based on this information, the results show how ID3 is involved in BMP signaling, which transpires in the pathogenesis of human PAH [63]. Furthermore, Lowery et al. evaluated pulmonary expression of ID proteins in a mouse model of a hypoxiainduced PH. Results showed selective induction of ID1 and ID3 expression in hypoxic VSMCs in vivo. Additionally, expression of ID1 and ID3 are increased by hypoxia in cultured pulmonary VSMCs in BMP-dependent nature. $\mathrm{PH}$ response to chronic hypoxia is dim between wild type and id1 null mice. This is connected with a compensatory rise in ID3 but not ID2 expression in pulmonary VSMCs of $i d 1$ null mice. Taken together, these findings indicate that expression of IDI and ID3 is regulated in a BMP-dependent fashion in hypoxic pulmonary VSMCs. ID1 and ID3 may also play compliant function in regulating $\mathrm{BMP}$-contingent VSMC response to chronic hypoxia [64].

Yang et al. investigated ID protein expression in human PASMCs by immunoblotting and real-time PCR. ID3 expression in pulmonary vessels was investigated in BMPRII mutant mice and in patients with heritable PAH. BMP4 and BMP induced mRNA expression of IDI, ID2, and ID3. The BMP-stimulated initiation of IDI and ID3 was evidently decreased in BMPR-II mutant PASMCs and in control PASMCs succeeding siRNA suppression of BMPR-II. Pulmonary arteries in bmpr2 mutant mice and patients with heritable $\mathrm{PAH}$ exhibited decreased levels of ID3 compared with control subjects. Furthermore, lentiviral ID3 overexpression reduced cell cycle progression and inhibited proliferation of PASMCs. Based on these lines of evidence, ID3 is one of the ID proteins considered as critical downstream effector of BMP signaling in PASMCs. Both ID1 and ID3 regulate proliferation of PASMCs via cell cycle inhibition, which may be intensified by inflammatory stimuli [9]. Gender also plays a large role in PAH development. Women develop PAH more frequently than men. Female non-PAH heritable PASMCs presented decreased messenger RNA and protein expression of BMPR2, SMAD1, ID1, and ID3. Phospho-SMAD1,5,8 and ID protein induction by BMP4 was also decreased in female heritable PASMCs. In male heritable PASMCs, estrogen decreased messenger RNA and expression. The 
TABLE 1: ID3 and PAH \& HHT described in the scientific literature.

\begin{tabular}{|c|c|c|c|}
\hline ID3 Associated Study Title & Authors & Year & Disease \\
\hline $\begin{array}{l}\text { Dysregulated bone morphogenetic protein } \\
\text { signaling in monocrotaline-induced } \\
\text { pulmonary arterial hypertension }\end{array}$ & Morty et al. & 2007 & PAH \\
\hline $\begin{array}{l}\text { ID family protein expression and regulation } \\
\text { in hypoxic pulmonary hypertension }\end{array}$ & Lowery et al. & 2010 & $\mathrm{PH}$ \\
\hline $\begin{array}{l}\text { BMP induces EphrinB2 expression in } \\
\text { endothelial cells through an } \\
\text { Alk1-BMPRII/ActRII-ID1/ID3-dependent } \\
\text { pathway: implications for hereditary } \\
\text { hemorrhagic telangiectasia type II }\end{array}$ & Kim et al. & 2012 & HHT \\
\hline $\begin{array}{l}\text { Id proteins are critical downstream } \\
\text { effectors of BMP signaling in human } \\
\text { pulmonary arterial smooth muscle cells }\end{array}$ & Yang et al. & 2013 & PAH \\
\hline $\begin{array}{l}\text { Sex affects bone morphogenetic } \\
\text { protein type II receptor signaling in } \\
\text { pulmonary artery smooth muscle } \\
\text { cells }\end{array}$ & Mair et al. & 2015 & PAH \\
\hline $\begin{array}{l}\text { ID3 contributes to the acquisition of } \\
\text { molecular stem cell-like signature in } \\
\text { microvascular endothelial cells: its } \\
\text { implication for understanding microvascular } \\
\text { diseases }\end{array}$ & Das et al. & 2015 & IPAH, PAH \\
\hline $\begin{array}{l}\text { ID3, estrogenic chemicals, and the } \\
\text { pathogenesis of tumor-like proliferative } \\
\text { vascular lesions }\end{array}$ & Avecilla V. & 2017 & PAH, HHT \\
\hline $\begin{array}{l}\text { The role of ID3 and PCB153 in the } \\
\text { hyperproliferation and dysregulation of } \\
\text { lung endothelial cells }\end{array}$ & Doke MA. & 2018 & PAH \\
\hline
\end{tabular}

estrogen metabolite 4-hydroxyestradiol decreased phosphoSMAD1,5,8 and ID expression in female heritable PASMCs while increasing these in males corresponding with a decreased proliferative effect in male heritable PASMCs [10].

ID3 has also been shown to transcriptionally reprogram lung endothelial cells via induction of proliferation and environmental toxicant PCB153. Committed ectopic ID3 expression in lung endothelial cells contributed to endothelialmesenchymal transition, cell migration, and cell proliferation. Using an established method to measure aberrant hyperproliferation of endothelial cells in PAH patients, Doke showed that established ectopic expression of ID3 increased the size and number of vascular spheres. Using ChIPSequence and RNA-Sequence methodology, ID3 is shown to be a part of a more general mechanism of transcriptional regulation. The ChIP-Sequence data showed that an important preference of ID3 binding to motifs connected with transcription factors: BC11A, PRDM1, SMAD4, FOXJ3, IRF4 ZBTB6, GATA1, IRF1, and STAT2 [65]. Additionally both $\mathrm{PAH}$ and HHT have been understood to be involved with ID3 in a vascular remodeling and dysfunction capacity. Gene expression and machine learning analysis exhibited ID3 as candidate target genes in PAH and HHT tissue and blood samples. ID3 and candidate target genes including $A B C B 6$, ACP1, BYSL, CAD, CDH15, DCBLD2, DHRS3, DNMT1, ID3, MCM4, and NDUFA7 were shown to be essential to various vascular remodeling pathways such as focal adhesion, oxidative phosphorylation, and cell cycle [66]. Lastly, using an angiogenesis model, Kim et al. found that $A L K 1$ ligand BMP9 induces EPHRINB2 in an in vitro model of HHT type 2. BMP9 stimulates both ID1 and ID3, which are both essential for full initiation of EPHRINB2. Loss of EPHRINB2 and $A L K 1$ caused an increased arterial-venous anastomosis, while loss of $A L K 1$ not EPHRINB2 demonstrates an increased expression of VEGFR2 and development. It is also shown that BMP9 blocks EC development and is reliant on BMPRII/ACTRII, ID1/ID3, and ALK1. Taken together, loss of $A L K 1$ blocks BMP9 signaling which results in decreased expression of EPHRINB2, misregulated EC development and anastomosis, and heightened VEGFR2 expression [8]. Based on the scientific evidence that links ID3 with both PAH and HHT, a schematic representation can be understood of how ID3 can influence these disease outcomes from a mechanistic approach as summarized in Figure 3. Additional research is necessary in order to completely reveal how these molecular communications between ID3 and PAH/HHT pathways impact these disease results. 




FIgURE 3: Diagram of how transcriptional regulator ID3 affects various pathways in HHT and PAH. Pathways included are ALK1/SMAD1-5, ALK/SMAD2-3, NOTCH, EPHRINB2-VEGFR2, and ALK1/ACTR2 via BMP or TGF- $\beta$ signaling.

\section{Conclusion}

Based on the existing literature, ID3 has shown to be connected with both PAH and HHT. Various studies have reported individual associations between ID3-PAH and ID3HHT, respectively; however, the combination of all three is rare but may have strong implications on their outcomes. ID3 is a transcriptional regulator seen to be essential in the promotion of cell cycle progression, endothelial cell activation, and embryonic vasculogenesis. Both diseases can be a result of mutations affecting various signaling pathways such as TGF- $\beta$ and BMP, vital for processes such as angiogenesis. Clinical indicators may not be specific but primary diagnosis is significant for the applicable treatment and prognosis. Thus, the overall understanding of the interactions between ID3 and these diseases is critical to the healthcare and scientific community working with PAH or HHT patients.

\section{Conflicts of Interest}

The author declares that they have no conflicts of interest.

\section{References}

[1] D. Sakurai, N. Tsuchiya, and A. Yamaguchi, "Crucial role of inhibitor of DNA binding/differentiation in the vascular endothelial growth factor-induced activation and angiogenic processes of human endothelial cells," The Journal of Immunology, vol. 173, no. 9, pp. 5801-5809, 2004.
[2] D. Lyden, A. Z. Young, D. Zagzag et al., "Id1 and Id3 are required for neurogenesis, angiogenesis and vascularization of tumour xenografts," Nature, vol. 401, no. 6754, pp. 670-677, 1999.

[3] Q. Felty and N. Porther, "Estrogen-induced redox sensitive Id3 signaling controls the growth of vascular cells," Atherosclerosis, vol. 198, no. 1, pp. 12-21, 2008.

[4] G. Eelen, P. De Zeeuw, M. Simons, and P. Carmeliet, "Endothelial cell metabolism in normal and diseased vasculature," Circulation Research, vol. 116, no. 7, pp. 1231-1244, 2015.

[5] Y. He, Y. Yao, S. E. Tsirka, and Y. Cao, "Cell-culture models of the blood-brain barrier," Stroke, vol. 45, no. 8, pp. 2514-2526, 2014.

[6] V. Avecilla, M. Doke, and Q. Felty, "Contribution of inhibitor of dna binding/differentiation-3 and endocrine disrupting chemicals to pathophysiological aspects of chronic disease," BioMed Research International, vol. 2017, Article ID 6307109, 22 pages, 2017.

[7] S. K. Chakrabarti, B. K. Cole, Y. Wen, S. R. Keller, and J. L. Nadler, "12/15-Lipoxygenase products induce inflammation and impair insulin signaling in 3t3-11 adipocytes," Obesity, vol. 17, no. 9, pp. 1657-1663, 2009.

[8] J.-H. Kim, M. R. Peacock, S. C. George, and C. C. W. Hughes, "BMP9 induces EphrinB2 expression in endothelial cells through an Alk1-BMPRII/ActRII-ID1/ID3-dependent pathway: Implications for hereditary hemorrhagic telangiectasia type II," Angiogenesis, vol. 15, no. 3, pp. 497-509, 2012.

[9] J. Yang, X. Li, Y. Li et al., "Id proteins are critical downstream effectors of BMP signaling in human pulmonary arterial smooth muscle cells," American Journal of Physiology-Lung Cellular and Molecular Physiology, vol. 305, no. 4, pp. L312-L321, 2013. 
[10] K. M. Mair, X. D. Yang, L. Long et al., "Sex affects bone morphogenetic protein type ii receptor signaling in pulmonary artery smooth muscle cells," American Journal of Respiratory and Critical Care Medicine, vol. 191, no. 6, pp. 693-703, 2015.

[11] R. R. Lim, A. Tan, Y.-C. Liu et al., "ITF2357 transactivates Id 3 and regulate TGF $\beta /$ BMP7 signaling pathways to attenuate corneal fibrosis," Scientific Reports, vol. 6, article no. 20841, 2016.

[12] Y. Shi and J. Massagué, "Mechanisms of TGF- $\beta$ signaling from cell membrane to the nucleus," Cell, vol. 113, no. 6, pp. 685-700, 2003.

[13] M.-J. Goumans, F. Lebrin, and G. Valdimarsdottir, "Controlling the angiogenic switch: a balance between two distinct TGF- $\beta$ receptor signaling pathways," Trends in Cardiovascular Medicine, vol. 13, no. 7, pp. 301-307, 2003.

[14] B. Gore, M. Izikki, O. Mercier et al., "Key role of the endothelial TGF- $\beta$ /ALK1/endoglin signaling pathway in humans and rodents pulmonary hypertension," PLoS ONE, vol. 9, no. 6, Article ID e100310, 2014.

[15] J. Yang, X. Li, and N. W. Morrell, "Id proteins in the vasculature: From molecular biology to cardiopulmonary medicine," Cardiovascular Research, vol. 104, no. 3, pp. 388-398, 2014.

[16] L. Pan, S. Sato, J. P. Frederick, X.-H. Sun, and Y. Zhuang, "Impaired immune responses and B-cell proliferation in mice lacking the Id3 gene," Molecular and Cellular Biology, vol. 19, no. 9, pp. 5969-5980, 1999.

[17] P. Poulsen, A. Vaag, K. Kyvik, and H. Beck-Nielsen, "Genetic versus environmental aetiology of the metabolic syndrome among male and female twins," Diabetologia, vol. 44, no. 5, pp. 537-543, 2001.

[18] D. Fraidenraich, E. Stillwell, E. Romero et al., "Rescue of cardiac defects in Id knockout embryos by injection of embyonic stem cells," Science, vol. 306, no. 5694, pp. 247-252, 2004.

[19] R. W.-S. Lim and J.-M. Wu, "Molecular mechanisms regulating expression and function of transcription regulator "inhibitor of differentiation 3",' Acta Pharmacologica Sinica, vol. 26, no. 12, pp. 1409-1420, 2005.

[20] A. Lasorella, R. Benezra, and A. Iavarone, "The ID proteins: Master regulators of cancer stem cells and tumour aggressiveness," Nature Reviews Cancer, vol. 14, no. 2, pp. 77-91, 2014.

[21] A. Lasorella, T. Uo, and A. Iavarone, "Id proteins at the crossroad of development and cancer," Oncogene, vol. 20, no. 58, pp. 8326-8333, 2001.

[22] D. A. Loveys, M. B. Streiff, and G. J. Kato, "E2A basic-helix-loophelix transcription factors are negatively regulated by serum growth factors and by the Id3 protein," Nucleic Acids Research, vol. 24, no. 14, pp. 2813-2820, 1996.

[23] Y. Liu, M. Encinas, J. X. Comella, M. Aldea, and C. Gallego, "Basic helix-loop-helix proteins bind to TrkB and p21Cip1 promoters linking differentiation and cell cycle arrest in neuroblastoma cells," Molecular and Cellular Biology, vol. 24, no. 7, pp. 2662-2672, 2004.

[24] S. Forrest and C. McNamara, "Id family of transcription factors and vascular lesion formation," Arteriosclerosis, Thrombosis, and Vascular Biology, vol. 24, no. 11, pp. 2014-2020, 2004.

[25] A. M. Taylor, F. Li, P. Thimmalapura et al., "Hyperlipemia and oxidation of LDL induce vascular smooth muscle cell growth: An effect mediated by the HLH factor Id3," Journal of Vascular Research, vol. 43, no. 2, pp. 123-130, 2006.

[26] K. Langlands, X. Yin, G. Anand, and E. V. Prochownik, "Differential interactions of Id proteins with basic-helix-loophelix transcription factors," The Journal of Biological Chemistry, vol. 272, no. 32, pp. 19785-19793, 1997.
[27] J. K. Das, N. F. Voelkel, and Q. Felty, "ID3 contributes to the acquisition of molecular stem cell-like signature in microvascular endothelial cells: Its implication for understanding microvascular diseases," Microvascular Research, vol. 98, pp. 126-138, 2015.

[28] N. Galiè, M. Humbert, J.-L. Vachiery et al., "2015 ESC/ERS guidelines for the diagnosis and treatment of pulmonary hypertension: The joint task force for the diagnosis and treatment of pulmonary hypertension of the european society of cardiology (ESC) and the european respiratory society (ERS): Endorsed by: Association for european paediatric and congenital cardiology (AEPC), international society for heart and lung transplantation (ISHLT)," European Heart Journal, vol. 37, no. 1, pp. 67-119, 2016.

[29] F. Soubrier, W. K. Chung, R. Machado et al., "Genetics and genomics of pulmonary arterial hypertension," Journal of the American College of Cardiology, vol. 62, no. 25, pp. D13-D21, 2013.

[30] E. K. Larkin, J. H. Newman, E. D. Austin et al., "Longitudinal analysis casts doubt on the presence of genetic anticipation in heritable pulmonary arterial hypertension," American Journal of Respiratory and Critical Care Medicine, vol. 186, no. 9, pp. 892896, 2012.

[31] S. Graf, M. Haimel, M. Bleda et al., "Identification of rare sequence variation underlying heritable pulmonary arterial hypertension," Nature Communications, p. 9, 2018.

[32] E. Tillet and S. Bailly, "Emerging roles of BMP9 and BMP10 in hereditary hemorrhagic telangiectasia," Frontiers in Genetics, vol. 5, article no. 456, 2014.

[33] G. Wang, R. Fan, R. Ji et al., "Novel homozygous BMP9 nonsense mutation causes pulmonary arterial hypertension: A case report," BMC Pulmonary Medicine, vol. 16, no. 1, 2016.

[34] S. Velthuis, E. Buscarini, J. R. Gossage, R. J. Snijder, J. J. Mager, and M. C. Post, "Clinical implications of pulmonary shunting on saline contrast echocardiography," Journal of the American Society of Echocardiography, vol. 28, no. 3, pp. 255-263, 2015.

[35] S. O. Trerotola and R. E. Pyeritz, "PAVM embolization: an update," American Journal of Roentgenology, vol. 195, no. 4, pp. $837-845,2010$.

[36] E. Buscarini, H. Plauchu, G. Garcia Tsao et al., "Liver involvement in hereditary hemorrhagic telangiectasia: consensus recommendations," Liver International, vol. 26, no. 9, pp. 10401046, 2006.

[37] V. M. Vorselaars, S. Velthuis, R. J. Snijder, J. A. Vos, J. J. Mager, and M. C. Post, "Pulmonary hypertension in hereditary haemorrhagic telangiectasia," World Journal of Cardiology, vol. 7, pp. 230-237, 2015.

[38] M. E. Faughnan, V. A. Palda, G. Garcia-Tsao et al., "International guidelines for the diagnosis and management of hereditary haemorrhagic telangiectasia," Journal of Medical Genetics, vol. 48 , no. 2, pp. 73-87, 2011.

[39] H. Plauchu, J.-P. de Chadarevian, A. Bideau, and J.-M. Robert, "Age-related clinical profile of heredity hemorrhagic telangiectasia in an epidemiologically recruited population," American Journal of Medical Genetics, vol. 32, no. 3, pp. 291-297, 1989.

[40] J. McDonald, W. Wooderchak-Donahue, C. VanSant Webb, K. Whitehead, D. A. Stevenson, and P. Bayrak-Toydemir, "Hereditary hemorrhagic telangiectasia: Genetics and molecular diagnostics in a new era," Frontiers in Genetics, vol. 6, no. 1, 2015. 
[41] C. J. Gallione, G. M. Repetto, E. Legius et al., "A combined syndrome of juvenile polyposis and hereditary haemorrhagic telangiectasia associated with mutations in MADH4 ( SMAD4)," The Lancet, vol. 363, no. 9412, pp. 852-859, 2004.

[42] P. Bayrak-Toydemir and J. McDonald, "HHT mutation database," http://arup.utah.edu/database/HHT/, 2018.

[43] T. G. W. Letteboer, J. J. Mager, R. J. Snijder et al., "Genotypephenotype relationship in hereditary haemorrhagic telangiectasia," Journal of Medical Genetics, vol. 43, no. 4, pp. 371-377, 2006.

[44] M. Benzinou, F. F. Clermont, T. G. W. Letteboer et al., "Mouse and human strategies identify PTPN14 as a modifier of angiogenesis and hereditary haemorrhagic telangiectasia," Nature Communications, vol. 3, 2012.

[45] D. Montani, L. C. Price, B. Girerd et al., "Fatal rupture of pulmonary arteriovenous malformation in hereditary haemorrhagic telangiectasis and severe PAH," European Respiratory Review, vol. 18, no. 111, pp. 42-46, 2009.

[46] T. Ota, M. Fujii, T. Sugizaki et al., “Targets of transcriptional regulation by two distinct type I receptors for transforming growth factor- $\beta$ in human umbilical vein endothelial cells," Journal of Cellular Physiology, vol. 193, no. 3, pp. 299-318, 2002.

[47] L. Chenggang, I. N. Hampson, L. Hampson, P. Kumar, C. Bernabeu, and S. Kumar, "CD105 antagonizes the inhibitory signaling of transforming growth factor $\beta 1$ on human vascular endothelial cells," The FASEB Journal, vol. 14, no. 1, pp. 55-64, 2000.

[48] S. Tual-Chalot, M. Mahmoud, K. R. Allinson et al., "Endothelial depletion of Acvrll in mice leads to arteriovenous malformations associated with reduced endoglin expression," PLoS ONE, vol. 9, no. 6, 2014.

[49] N. W. Morrell, S. Adnot, S. L. Archer et al., "Cellular and molecular basis of pulmonary arterial hypertension," Journal of the American College of Cardiology, vol. 54, no. 1, pp. S20-S31, 2009.

[50] C. E. van der Bruggen, C. M. Happé, P. Dorfmüller et al., "Bone morphogenetic protein receptor type 2 mutation in pulmonary arterial hypertension," Circulation, vol. 133, no. 18, pp. 17471760, 2016.

[51] Z. Huang, D. Wang, K. Ihida-Stansbury, P. L. Jones, and J. F. Martin, "Defective pulmonary vascular remodeling in Smad8 mutant mice," Human Molecular Genetics, vol. 18, no. 15, pp. 2791-2801, 2009.

[52] L. David, C. Mallet, S. Mazerbourg, J. Feige, and S. Bailly, "Identification of BMP9 and BMP10 as functional activators of the orphan activin receptor-like kinase 1 (ALK1) in endothelial cells," Blood, vol. 109, no. 5, pp. 1953-1961, 2007.

[53] L. Long, M. L. Ormiston, X. Yang et al., "Selective enhancement of endothelial BMPR-II with BMP9 reverses pulmonary arterial hypertension," Nature Medicine, vol. 21, no. 7, pp. 777-785, 2015.

[54] N. W. Morrell, D. B. Bloch, P. Ten Dijke et al., "Targeting BMP signalling in cardiovascular disease and anaemia," Nature Reviews Cardiology, vol. 13, no. 2, pp. 106-120, 2016.

[55] W. L. Wooderchak-Donahue, J. McDonald, B. O'Fallon et al., "BMP9 mutations cause a vascular-anomaly syndrome with phenotypic overlap with hereditary hemorrhagic telangiectasia," American Journal of Human Genetics, vol. 93, no. 3, pp. 530537, 2013.

[56] B. Girerd, D. Montani, F. Coulet et al., "Clinical outcomes of pulmonary arterial hypertension in patients carrying an ACVRL1 (ALK1) mutation," American Journal of Respiratory and Critical Care Medicine, vol. 181, no. 8, pp. 851-861, 2010.
[57] R. D. Machado, L. Southgate, C. A. Eichstaedt et al., "Pulmonary arterial hypertension: a current perspective on established and emerging molecular genetic defects," Human Mutation, vol. 36, no. 12, pp. 1113-1127, 2015.

[58] E. M. de Gussem, C. P. Edwards, A. E. Hosman et al., "Life expectancy of parents with hereditary haemorrhagic telangiectasia," Orphanet Journal of Rare Diseases, vol. 11, no. 1, 2016.

[59] R. L. Benza, M. Gomberg-Maitland, D. P. Miller et al., "The REVEAL registry risk score calculator in patients newly diagnosed with pulmonary arterial hypertension," Chest, vol. 141, no. 2, pp. 354-362, 2012.

[60] V. Albiñana, M. Bernabeu-Herrero, R. Zarrabeitia, C. Bernabeu, and L. Botella, "Estrogen therapy for hereditary haemorrhagic telangiectasia (HHT): Effects of raloxifene, on Endoglin and ALK1 expression in endothelial cells," Thrombosis and Haemostasis, vol. 103, no. 03, pp. 441-451, 2017.

[61] M. E. Pugh and A. R. Hemnes, "Pulmonary hypertension in women," Expert Review of Cardiovascular Therapy, vol. 8, no. 11, pp. 1549-1558, 2014.

[62] E. Yaniv, M. Preis, J. Shvero, B. Nageris, and T. Hadar, "Antiestrogen therapy for hereditary hemorrhagic telangiectasia - A long-term clinical trial," Rhinology, vol. 49, no. 2, pp. 214-216, 2011.

[63] R. E. Morty, B. Nejman, G. Kwapiszewska et al., "Dysregulated bone morphogenetic protein signaling in monocrotalineinduced pulmonary arterial hypertension," Arteriosclerosis, Thrombosis, and Vascular Biology, vol. 27, no. 5, pp. 1072-1078, 2007.

[64] J. W. Lowery, A. L. Frump, L. Anderson, G. E. DiCarlo, M. T. Jones, and M. P. de Caestecker, "ID family protein expression and regulation in hypoxic pulmonary hypertension," American Journal of Physiology-Regulatory, Integrative and Comparative Physiology, vol. 299, no. 6, pp. R1463-R1477, 2010.

[65] M. A. Doke, "The role of ID3 and PCB153 in the hyperproliferation and dysregulation of lung endothelial cells," FIU Electronic Theses and Dissertations, vol. 3808, 2018, https:// digitalcommons.fiu.edu/etd/3808.

[66] V. E. Avecilla, "ID3, estrogenic chemicals, and the pathogenesis of tumor-like proliferative vascular lesions," FIU Electronic Theses and Dissertations, vol. 3519, 2017, https://digitalcommons .fiu.edu/etd/3519. 


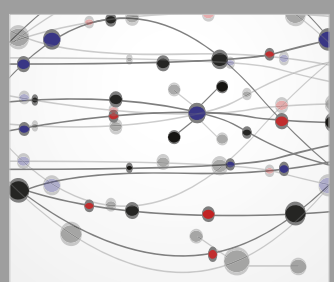

The Scientific World Journal
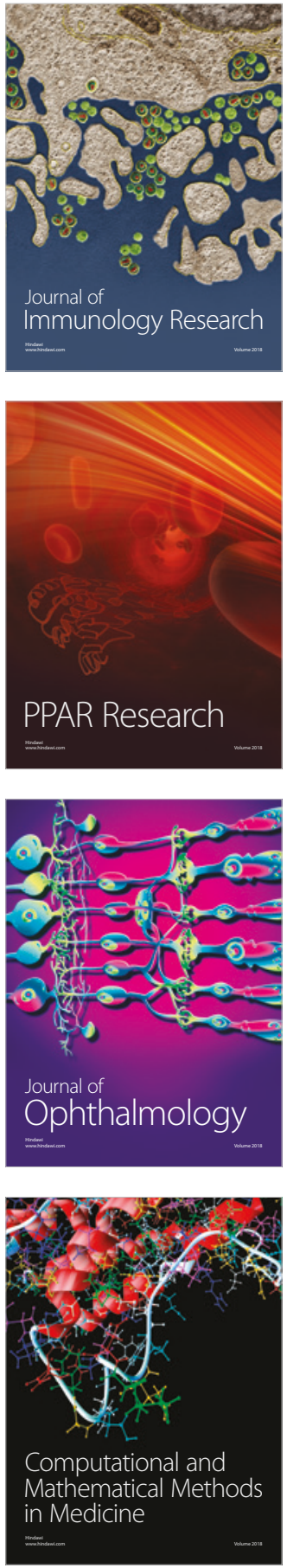

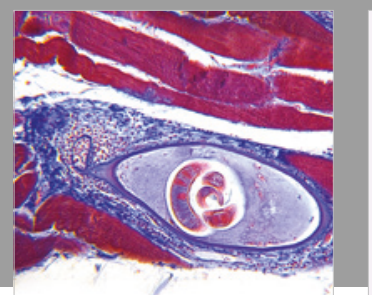

Gastroenterology Research and Practice

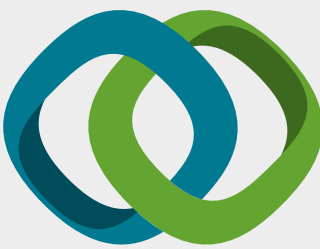

\section{Hindawi}

Submit your manuscripts at

www.hindawi.com
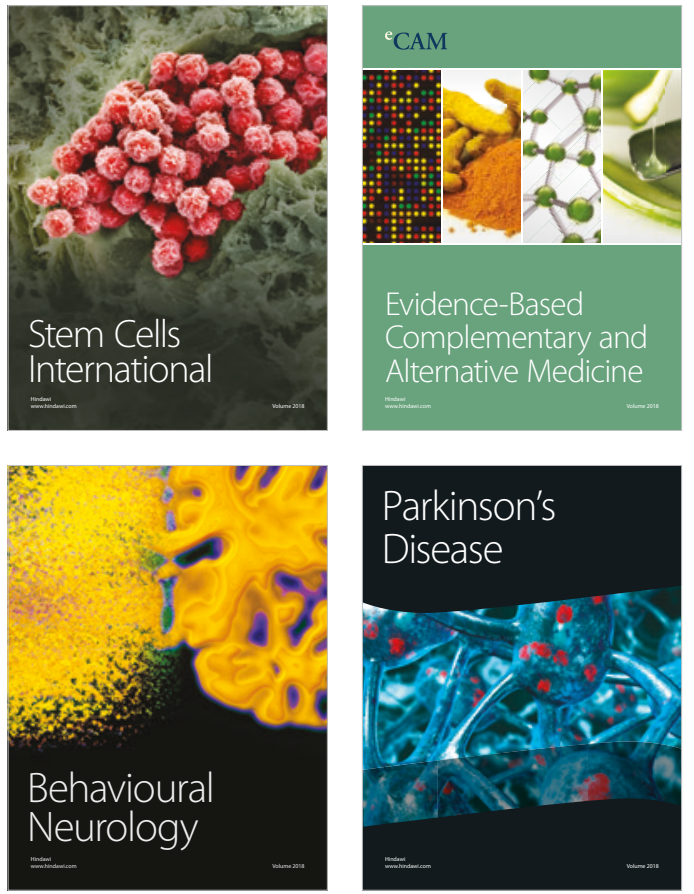

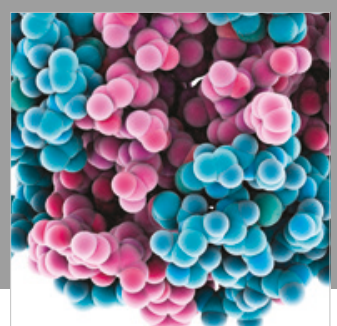

ournal of

Diabetes Research

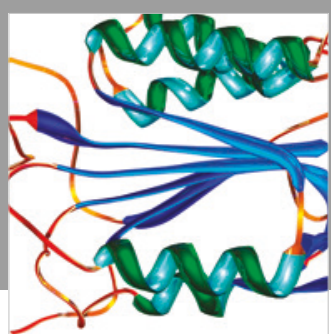

Disease Markers
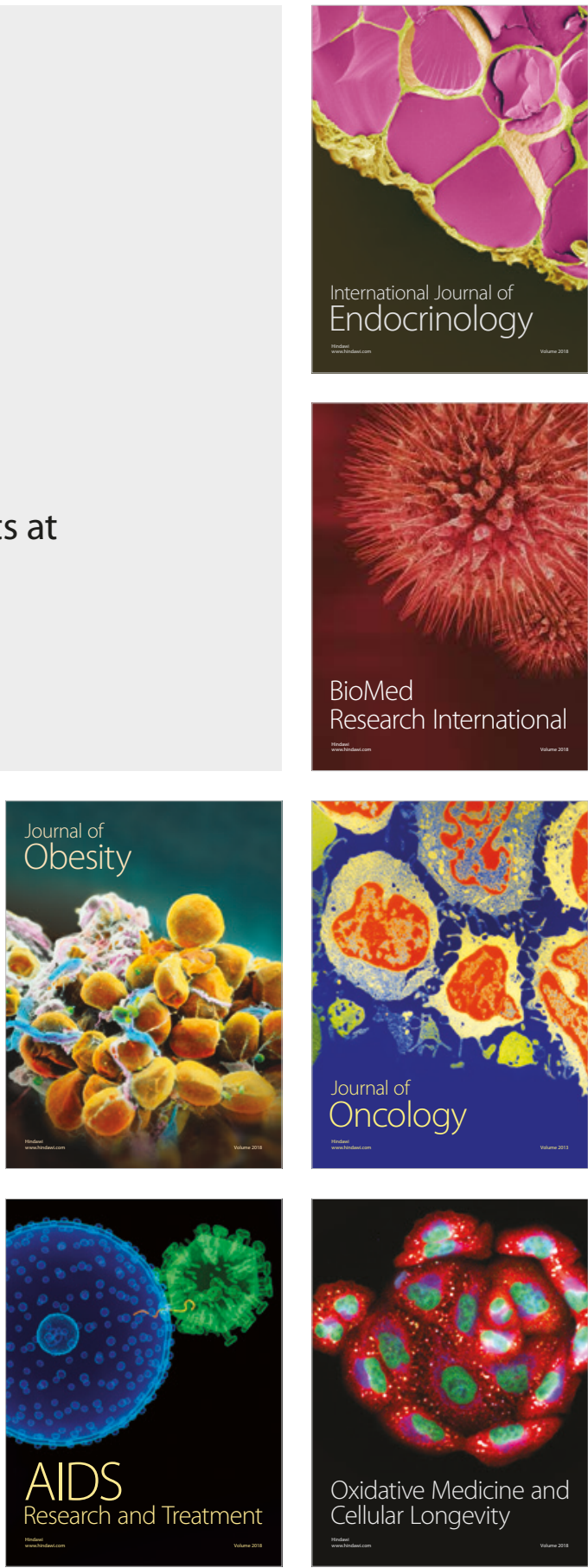